\title{
Study on the Problems and Countermeasures of Government Procurement in China
}

\author{
Liu Bin ${ }^{1}$; Zhang Yan²; Yi Mian ${ }^{3}$
}

\author{
1 JiangXi Technical College of Manufacturing, Department of Information Engineering; JiangXi \\ Nanchang; 330095 \\ 2 Jiangxi Technical College of Manufacturing, Department of Information Engineering; JiangXi \\ Nanchang; 330095 \\ 3 Jiangxi Technical College of Manufacturing, Department of Information Engineering; Jiangxi \\ Nanchang; 330095
}

Keywords: Government Procurement; Bidding; Existing Issues; Research on Countermeasures

\begin{abstract}
With the gradually deepening promotion of government procurement and rapid expansion on the scale, some unspoken rules under the socialist planned economy still work in some large or small areas. Undoubtedly, there still exist several issues in government bidding procurement today, such as, incomplete laws and rules, unstandardized budget, nontransparent procurement process, deficient relief mechanisms, and inadequate protection on national industry and their own brands. Besides, it is not suitable to the in-depth development of the socialist market economy, so researchers need to consider how to promote the reform and innovation and development of the government procurement system researchers .
\end{abstract}

\section{Introduction}

Since China's reform and opening up, with the establishment of the socialist market economic system, commodity market has achieved an unprecedented development and market competition, especially in recent years, there has become a buyer's market, which has laid a good foundation for the bidding procurement to carry out the procurement. In the government and the public sectors, there already has possessed an economic and institutional foundation. However, with the development of bidding purchase, a variety of issues will also happen attendantly on the government bidding process, and have had a major impact on the healthy operation of the economy.

In foreign countries, bidding, as a normative procurement method, has also been perfected with the economic development, the state's macro capability enhancement, a considerable degree on purchases, deepening of the state functions after nearly 100 years of gradual improvement. Since the past two decades, all the countries in the world have a further understanding on the role that bidding procurement can promote the fair competition of world trade as well as prevent corruption. However, the specific executing methods of the bidding procurement vary across countries.

Therefore, at the present stage of China, the government bidding is still in the initial and exploratory stage: bidding system is not perfect; state-owned assets account for a large proportion; state-owned enterprises institutions account for a large proportion; there is no normative tradition that public procurement tender takes; the political, economic and cultural development of all regions is very uneven. Faced with this reality, it becomes significant that the government need to strengthen its control and management on bidding procurement.

\section{The Status and Problems of Government Bidding Procurement}

With the gradual formation and development of world economic integration, the government bidding procurement gradually changes from closeness to openness, and becomes an important 
part of the world trade liberalization. Researchers should base on China's basic national conditions, sum up and learn from the implementing experience of the developed countries in government bidding process. Moreover, in accordance with relevant provisions of the national Bidding Law and the Interim Regulations on Government Procurement Management of the Ministry of Finance, researchers shouldconstantly improve the government procurement system.

An analysis the situation of government procurement system. China's bidding career generates along with the transformation from socialist commodity economy to socialist market economy. It meets the requirements of international conventions, and also adapts to China's national conditions and and has a gradual impact on the development of China's economy.

In recent years, with the reform of the bidding and the promotion of China's financial system, the government began a pilot project to take bidding procurement as the main mode. Currently, the government bidding procurement mainly carries out on medical equipment, office supplies, official vehicles and related services and other aspects.

The government bidding is a new thing for China, who started late but developed rapidly since the pilot carried out in some places in 1996, and had reached 360 billion Yuan in 2007.

\section{The status and problems of government bidding procurement}

The law system of government bidding procurement is not complete. Only to form a sound legal system of government bidding procurement can researchers achieve a lawful and standardized supervision on the government procurement. Since the Government Procurement Law issued in 2003, the prototype of the government bidding has basically formed. In addition, through the efforts of the past few years, China's government procurement bidding procedures have formed a relatively complete organization and management system on the operating instruction, budget management and payment and performance appraisal management, but from the overall operating and running situation, the laws and regulations in this field are still not complete, and there still need further modification and improvement in many areas.

The supervision and management system of government bidding procurement is not complete. Currently, there are still imperfections on the supervision and management system of government bidding. In accordance with the Government Procurement Law, "the government bidding regulatory agencies, all levels of government Ministry of Finance, and the Ministry of Finance should fulfill the regulatory responsibility in accordance with the law in the government bidding procurement activities." However, the financial sector have occurred many problems in the exercise of regulatory functions. Firstly, in the specific procurement activities, some local government's financial sector and the actual implementation of government bidding procurement agent department had not set separately, but achieved the procurement and regulation in the form of a sector, which resulted the uselessness in the supervision of the government's bidding; secondly, in the particular procurement process, the financial sector are lack of the coordination with other regulators like discipline inspection and auditing, which resulted in the manual blockade procurement market in some areas, discrimination, exclusion overseas suppliers and other government protectionism behaviors, and there also exists the issues that the examination of a particular vendor qualification is too simple in the bidding process, and business and government officials have secret operations in collusion.

The electronic level of government bidding system is quite low. In 2004, Electronic Signature Law, one of the most important legal documents in the Internet field, was promulgated, which greatly promoted the government bidding electronic development process. In order to accelerate the pace of building modern government bidding, China plans to establish a fair trading platform of government bidding and purchasing information. However, there still remain many problems in China's current e-government bidding and purchasing, which mainly appear in the following points: Firstly, the government's electronic bidding laws and regulations need to be 
improved; secondly, the collaboration of government bidding and purchasing on e-business is difficult, and the platform of unified national electronic government bidding procurement has not been established.

The training mechanism of government bidding employees needs to be improved. Government bidding and purchasing is a very complex activity undertaken by the government, which requires government procurement officials can consider various aspects of the issues and make an analysis of the interests of all parties.

However, the government bidding sectors are lack of specialized personnel; the overall quality of procurement staff is low; they are lack of ideas on administration according to law and legal procurement; they can not resolve problems promptly and effectively, all of which will limit the development of China's government bidding career.

The green procurement system of government has not been established. In recent years, as China pays more and more attention to environmental protection, more and more attention to sustainable development of economic and ecological environment, in order to achieve this goal, China began to promote and encourage and support the development of circular economy, which mainly embodies as the implementation of "green public procurement" policy in government bidding procurement. Although most parts of China have requested the government' $\mathrm{s}$ bidding to follow the principles of environmental protection, then the above policy goals have no viable solutions because that the thorough green procurement implementation plan and procurement rules have not been established. In general, at this stage green procurement plan of the government have no real conditions to fully implement, and then the role of the government procurement is restricted.

\section{The Measures and Proposals to Complete Government Bidding Procurement}

Establish a sound management mechanism on government bidding procurement. China wants to explore government bidding procurement through the theoretical and practical aspects, to discover and solve problems, and to formulate practical implementing plans in order to achieve the objectives of government bidding procurement. This can be tested the theory through the establishment of a pilot, if beneficial results achieved, researchers should legalize as soon as possible, and expand the scope of the pilot, and gradually build up government procurement system that not only has international standards but also has modern Chinese characteristics. This can be operated from the following two aspects:

First, improve the establishment of legal system and enhance the legislative levels of government bidding procurement.

Second, establish and improve a sound legal system which regards the Government Procurement Law as the subject and to coordinate with related laws and regulations.

Improve the government's bidding supervision system in China. First, build an internal supervision system according to law. Whether the functions of government bidding procurement can be achieved, researchers should depend on whether all aspects of the procurement activities can proceed according to the law and regulations, and that requires an independent supervisory department to exercise effective supervision.

Second, improve the external supervisory mechanism of a government bidding and purchasing. On the organization and related operational procedures, researchers should establish a mechanism which restrict mutually but separate from each other; on the function structure, researchers should guarantee the mutual separation of supervision and purchasing department; on the specific operation, researchers should ensure the mutual separation of the procurement, payment, inspection and arbitration of disputes with other sectors, and gradually establish a monitoring mechanism of parties with checks and balances.

Improve the electronic level of government bidding procurement. In order to increase the 
electronic degree of government bidding procurement, researchers should follow the guidelines of unified supervision and implementation step by step, and continuously push forward the establishment of a operating system with unified basic database systems and integrating processes, and multi-level monitoring system of government bidding and purchasing management platform. Therefore, researchers will regard scientific management of completing the government bidding process as a working objective.

Cultivate specialized government bidding and purchasing professionals and to improve the efficiency of government bidding procurement. First, establish a standardized personnel access system.

Second, strengthen the training of existing staff in procurement expertise, to implement training of different categories to procurement company leader, financial officers, agents, suppliers, government public affairs and public welfare personnel to ensure that the procurement team is professional and specialized.

Third, strengthen the ideological and moral education of procurement staff. Only when employees have high ideological and moral consciousness can they make the procurement process truly open, fair, just, honest and efficient.

Expand the scale of green procurement and to effectively perform the function to guide green consumption. Firstly, researchers must improve the relevant laws to make green insurance system formed, and in compliance with the laws and regulations of the premise, in the same conditions of service indicators, technology, regard the formulation of green list of products as a measure to further guidance green procurement.

Secondly, the procuring goods need to have a green flag as a prerequisite, and then to develop and publish a green commodity procurement catalog.

Thirdly, publish green procurement information timely and gradually establish an information platform of green procurement information in order to supervised by relevant functional departments.

Finally, encourage the production and development of high-quality green products. Because companies will increase research and development costs, and production cost will increase safety and environmental protection, in order to protect the production and sale of green products, researchers can, to some extent, make necessary tilt for the production on the purchase price of green products by enterprises, so that manufacturers' enthusiasm for production will be improved.

\section{Conclusion}

Government bidding is a primary means of government procurement. The paper affirms the achievements of the way and analyzes some existing bottlenecks in the development of current government procurement career, and then consider from the ideas that discover the problem and then solve it, through the effective analysis of the issue, and finally build control system of government bidding procurement. Researchers reach the following conclusions:

(1) The implementation of government bidding procurement in China have very important significance on many aspects, such as to improve the decision-making level of a project, to ensure scientific and timeliness decision-making and to provide a fair competitive environment, etc.

(2) It is true that the affirmative bidding procurement is advantageous, while the use of this method is still in the process of continuous improvement. Be clear of the existing common problems during government bidding process and to control and improve with a certain target, all these are priorities during the healthy development of China's bidding procurement career.

(3) For the outstanding problems that exist in government bidding procurement, researchers should take the appropriate control measures at each stage.

(4) After China joining the WTO, the government bidding procurement is faced with the challenge of globalization and increasing internationalization. In order to make government 
bidding process increasingly simple and more transparent, China must continue to strengthen the government bidding and purchasing, improve the supervision mechanism, and open up the government bidding procurement market constantly.

\section{References}

[1] Chu Xinli. Reconsideration the Issue of Government Procurement of China [J]. Business Economics. 2011,111-123.

[2] Xiong Jinwen, Chen Rong, Yang Peng, The Research on the Policy How United States Government Procurement Support Domestic Enterprises [J]. Chinese Finance 2011, (3) 20-33

[3] Zhang Zhiquan, An Analysis of the Electronization of Government Procurement [J]. Economic Review 2011, (1) 07-11.

[4] Qiu Zhihua. Thoughts on Improving Government Procurement System [J]. Beijing Vocational College of Finance and Trade Journal. 2011, (9) 122-139.

5] Huang Mingjin, On Actively Build Government Procurement Risk Control Mechanism [J]. Chinese Government Procurement 2011, (5) 45-78.

[6] Lv Zenghui, An analysis the Situation and Problem of China's Government Procurement [D] Inner Mongolia: Economy and Technology Paper of Inner Mongolia University of Finance, 2012 01-06.07-14 .

[7] Ji Yingdong. Wang Xiuyan, On Risk and Prevention of Government Bidding. [J]. Economic Observer 201102-14.

[8] Zhang Yaming. On the Strategies to Prevent Government Bidding Credit Risk. [J]. Adminis trative Forum 2012 (3), 43-65.

[9] Zhang Zhiquan, An Analysis of Electronization of the Government Procurement. [J]. Economic Review 2011 (1), 04-25.

[10] Qu Xingbei, Ob the Problems and Countermeasures of China's Government Procurement System [D] Jilin: The Technical and Economic Paper of Jilin University 201309-18.

[11] Russell Forbes.Government Purchasing. New York: Happren Brothers Publishers, 2012 123-124.

[12] W.J.Baumol Noteson. The Theory of Government. Procurement Economic Journal, 2013 (2): 96-100.

[13] James M.Buchanan, Robert D.Tollision. Toward a Theory the Rent-Seeking Society. Texas: Texas A\&M University Press, 2011 73-81. 